\title{
Recovery of photosynthesis, sucrose metabolism, and proteolytic enzymes in Kandelia obovata from rare cold events in the northernmost mangrove, China
}

Chunfang Zheng ${ }^{1}$, Yong Ye ${ }^{2}$, Weicheng Liu ${ }^{1 *}$, Jianwu Tang ${ }^{3 *}$, Chengnian Zhang $^{4}$, Jianbiao Qiu ${ }^{1}$ and Jinong Chen ${ }^{1}$

\begin{abstract}
Introduction: Understanding how mangroves respond to rare cold events has implications for both restoration and conservation under climate change scenarios. This study investigated the responses of photosynthesis and activities of key enzymes involving carbon and nitrogen metabolism at different ages of Kandelia obovata to a rare cold event in the winter of 2010.

Methods: This study took place on Ximen Island, Zhejiang Province, China. We measured the physiological recovery of 2-3-, 5-6-, 9-10- and 54-55-year-old K. obovata trees after freezing injury in February and March in 2011 and 2012, respectively.
\end{abstract}

Results: Chilling injury index and electrolyte leakage of $K$. obovata increased with increasing tree age in the winter of 2010, and electrolyte leakage in K. obovata at different ages in the winter of 2010 was far higher than that in the winter of 2011. The rare cold events significantly changed the recoveries of the leaf net photosynthetic rate (Pn) and stomatal conductance (Gs); ratios of chlorophyll a/chlorophyll b (Chl a/Chl b); contents of total soluble sugar (TSS), sucrose, free amino acid (FAA), and soluble protein; and activities of sucrose phosphate synthase (SPS), endopeptidase, and carboxypeptidase in K. obovata at different ages. These effects were mainly due to changes in the physiological mechanism in the 2-year-old trees. A clear decrease in $\mathrm{Pn}$ of the 2-year-old trees was observed in February 2011, as exemplified by reductions in ratios of $\mathrm{Chl} \mathrm{a/Chl} \mathrm{b}$ and chlorophyll/carotenoid (Chl/Car), as well as inhibition of the levels of TSS and FAA (osmotic substances). During recovery in 2011 and 2012, the activities of SPS and sucrose synthase (SS) were responsible for sucrose synthesis after the rare cold events in 2011, but only SPS activity was one of the main factors contributing to the metabolism of stachyose to sucrose without cold damage in 2012. Carboxypeptidase played a more important role than endopeptidase during protein hydrolysis after the rare cold events.

Conclusions: The results suggest that the recovery of photosynthetic capacity in K. obovata was changed after a rare cold event, which is associated with pigment components and activities of SS, SPS, and carboxypeptidase, especially the seedlings.

Keywords: Kandelia obovata, Photosynthesis, Sucrose synthase, Rare cold events, Peptidase

\footnotetext{
*Correspondence: |z|z|y2010@126.com; jimtang1999@gmail.com

'Wenzhou Ocean Research Institute, Zhejiang Key Laboratory of Exploitation

and Preservation of Coastal Bio-resource, Zhejiang Mariculture Research

Institute, Wenzhou 325000, China

${ }^{3}$ Nanji Islands National Marine Nature Reserve Administration, Pingyang,

China

Full list of author information is available at the end of the article
} 


\section{Introduction}

Mangroves are open ecosystems that straddle the land and the sea, from freshwater to seawater, providing diverse habitats for plant and animal species ( $\mathrm{Li}$ and Less 1997). They are one of the most productive ecosystems in the world and provide a variety of ecological and societal goods and services (Liu et al. 2014), such as nursing fishes (Levy et al. 2015), maintaining biodiversity (Thornton and Johnstone 2015), and absorbing pollution (Debenay et al. 2015). Despite their ecological relevance, mangroves that grow along the latitudinal extremes of their distribution in subtropical and tropical environments are extremely vulnerable to low temperature (Ellis et al. 2006). Low temperature can seriously affect the growth, development, nutrient resorption, and survival of mangroves in coastal tidal wetlands (McMillam 1971; Wang et al. 2011b). Global warming can result in mangrove forests migrating to higher latitudes, either naturally or with human-assisted migration (Field 1995; Gilman et al. 2008). However, extreme cold events may slow down this migration. For example, frost damage that occurred in 2008 resulted in the death of a significant number of mangrove seedlings introduced into the southeast coast of China and early drop of flowers and fruits of mature trees, thereby damaging the natural regeneration and reforestation of mangroves in the forthcoming 1 or 2 years (Chen et al. 2010). Thus, current physiological and ecological studies are focusing on the cold damage of mangroves. Kao et al. (2004) demonstrated that the leaves of Kandelia obovata Sheue, Liu \& Yong (2003) show a reduction in light-saturated photosynthetic rates, stomatal conductance, electron transport rates, and quantum yields of photosystem II after exposure to $15{ }^{\circ} \mathrm{C}$ for $1 \mathrm{~h}$. In recent years, combined with continuing research on cold damage in mangroves, the recovery of physiological and ecological functions of mangroves after low temperature stress has attracted increasing attention. Studies on the recovery from low temperatures mainly focused on extreme temperature and recovery time (Yang et al. 2001). However, the detailed impact of coldness on the physiology of mangroves has not been widely reported.

The most cold-tolerant mangrove is $K$. obovata in China. Its northernmost natural distribution in China is located in Fuding County, Fujian Province $\left(119^{\circ}\right.$ $55^{\prime}-120^{\circ} 43^{\prime} \mathrm{E}, 26^{\circ} 55^{\prime}-27^{\circ} 20^{\prime} \mathrm{N}$ ), and its plantation is located further north in Ximen Island, Zhejiang Province $\left(121^{\circ} 09^{\prime}-121^{\circ} 12^{\prime} \mathrm{E}, 28^{\circ} 19^{\prime}-28^{\circ} 21^{\prime}\right.$ $\mathrm{N})$. However, chilling damage is still one of the major factors restraining the introduction and expansion of $K$. obovata. At present, $K$. obovata introduced at different periods have survived in Ximen Island, Zhejiang Province,
China. In the winter of 2010, an exceptionally cold wave pervaded most regions in China, and this periodic frost also threatened the region of Wenzhou, Zhejiang Province, including Ximen Island (Wenzhou Municipal Meteorological Bureau: Wenzhou Climate Impact Assessment in 2010). Our previous study found that frost damage in the winter of 2010 significantly reduced the photosynthetic pigments and activities of antioxidant enzymes and interfered with ion absorption of $K$. obovata seedlings (introduced in 2008 and 2009) in Ximen Island (Zheng et al. 2013). However, current studies mainly focused on cold damages to mangrove forests. To date, the physiological and ecological impacts on mangrove recovery after cold injury in the winter have not been given sufficient attention. Understanding the recovery of mangrove forests after a cold stress is necessary to restore, protect, and assist migration mangroves. On December 17, 2010, the temperature in Ximen Island fell below freezing (minimum $-3.2{ }^{\circ} \mathrm{C}$ ). Successive cold temperature appeared since then in the winter of 2010. Afterwards, the leaves of $K$. obovata were found brown and wilted, and a higher mortality of 2-year-old seedlings was reported (Zhejiang Provincial Oceanic Disaster Bulletin in 2011). This event presented an opportunity to compare the recovery of $K$. obovata at different ages on sucrose metabolism, protein hydrolysis, and photosynthetic characteristics after winters that had cold events and those that did not have extreme low temperature, which is a subsequent work of Zheng et al. (2013). Information from this study will be helpful to define some physiological processes in order to understand the recovery mechanisms of mangroves, and the results provide a useful knowledge on how to better restore, protect, and transplant the mangrove tree in the future.

\section{Methods}

Study site

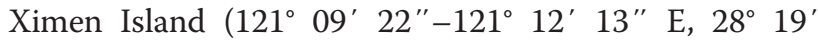
$\left.50^{\prime \prime}-28^{\circ} 21^{\prime} 33^{\prime \prime} \mathrm{N}\right)$, located in Yueqing City, Zhejiang Province, China, with a mean seawater temperature of $18.9{ }^{\circ} \mathrm{C}$ and a mean rainfall of $2043.1 \mathrm{~mm}$ per year, was selected as the study area. The study area is subject to semi-diurnal tides, with a mean tidal range of $5.15 \mathrm{~m}$. The annual mean air temperature is $18.7^{\circ} \mathrm{C}$, with the lowest temperature being $-5.1{ }^{\circ} \mathrm{C}$ (Meteorological Bureau of Wenzhou Municipality). Water salinity ranges between 26 and $29 \%$. The tidal flat is mainly silty clay. The silty clay contains $13-28 \mathrm{~g} \mathrm{~kg}^{-1}$ organic matter, $0.9-1.3 \mathrm{~g} \mathrm{~kg}^{-1}$ total $N, 48-65 \mathrm{mg} \mathrm{kg}^{-1}$ available $N, 10-25 \mathrm{mg} \mathrm{kg}^{-1}$ Olsen-P.

\section{Sampling}

In Ximen Island, the four selected $K$. obovata forests (which were all introduced from Fujian Province in China as seedlings) were planted in 2009, 2006, 2002, 
and 1957, with forest ages of 2, 5, 9, and 54 years in 2011, respectively. The areas of the 2-, 5-, 9- and 54year-old $K$. obovata forests were about 10, 11, 3, and $2 \mathrm{~km}^{2}$, respectively, and their average plant height were $0.3,1.0,1.5$, and $3.0 \mathrm{~m}$, respectively. Five individuals of $K$. obovata were randomly chosen for sampling in each age level. All sample areas had a relatively similar tide elevation.

Given the effects of cold air masses southward, the temperature of Yueqing City continued to fall from the afternoon of 14 December 2010, with the daily average temperature dropped to above $12{ }^{\circ} \mathrm{C}$. Snow appeared on 15 December 2010 . The temperature dropped to $0{ }^{\circ} \mathrm{C}$ on 16 December 2010 and $-1.4{ }^{\circ} \mathrm{C}$ on 17 December 2010 (data sourced from Wenzhou Climate Impact Assessment in 2010). In Ximen Island, the temperature dropped to $-3.2{ }^{\circ} \mathrm{C}$, which featured characteristics of a cold wave. The temperature of Ximen Island began to drop again on 24 December 2010, accompanied with sleet. The weather of the cold wave on 17 December 2010 and 24 December 2010 resulted in badly damaged mangroves. The cold temperature continued, which further aggravated the extent of damage. To determine the unique influence of rare cold events in mangroves, additional studies were carried out in the winter of 2011. Compared with 2010, no extremely cold event occurred in 2011. Daily changes in the mean temperature and minimum temperature were measured for Ximen Island from 2010 to 2012 (Fig. 1). The air temperature in the mangrove area of Ximen Island was continuously recorded at a frequency of $30 \mathrm{~min}$ using a HOBO Water Temperature pro v2 Data Logger (Onset Computer Corporation USA). During the cold events, we assessed the impacts on leaf physiological parameters (Zheng et al. 2013). Therefore, we could explain the different recoveries of leaves in the winter between 2010 and 2011 in this study. Based on the knowledge that mangroves can recover at temperature above $10{ }^{\circ} \mathrm{C}$ (non-cold stress temperature), physiological parameters of the second pairs of leaves at different ages was measured from 9:00 to 11:30 on 27 February 2011 (T2), 31 March 2011 (T3), 31 January 2012 (T4), 21 February 2012 (T5), and 31 March 2012 (T6). Meanwhile, the second pairs of leaves at different ages were obtained to determine the physiological parameters.

\section{Electrolyte leakage analysis}

The leaves of the 2-year-old $K$. obovata seedlings were dark brown on 31 January 2011 (T1), so samples were collected to determine electrolyte leakage. Other samples were also surveyed on T4. Electrolyte leakage was assayed based on the electric conductivity of the water extracts according to Bertin et al. (1996). In brief, two sets of leaf samples were cut into 1 -cm-long pieces and then placed in test tubes containing $30 \mathrm{~mL}$ of deionized water. The fragments were then transferred to test tubes containing $10 \mathrm{~mL}$ of deionized water. Immediately after transfer, the initial electrical conductivity $\left(C_{\mathrm{t} 0}\right)$ of the solution was measured using conductometry (Century Instruments, Chandigarh, India). The test tubes were then placed at $20{ }^{\circ} \mathrm{C}$ for $24 \mathrm{~h}$. The final conductivity $\left(C_{\mathrm{t} 1}\right)$ was measured. The test tubes were finally autoclaved for $30 \mathrm{~min}$ and cooled to room temperature for total conductivity measurement $\left(C_{\text {tot }}\right)$. Electrolyte leakage was calculated using the following equation: $C \%=\left(C_{\mathrm{t} 1}-C_{\mathrm{t} 0}\right) / C_{\mathrm{tot}} \times 100$.

\section{Chilling injury index analysis}

A cold damage survey was performed on T3, since symptoms of frost injury were obvious at this time. The chilling injury damage was calculated based on the method of Chen et al. (2011). The severity of the symptoms was assessed visually according to the following four-stage scale: $0=$ no leaf injury; $1=$ one third of the leaves showed injury; 2 = two third of the leaves showed injury; and 3 = all leaves showed injury. The chilling injury (CI) index was calculated using the following formula.

\section{Leaf gas exchange analysis}

Net photosynthetic rate $(P n)$ and stomatal conductance (Gs) were measured by a LI-6400 portable photosynthesis system (LiCor Inc., Lincoln, NE, USA) at a $\mathrm{CO}_{2}$ concentration of ca. $390 \pm 10 \mu \mathrm{mol} \mathrm{mol}{ }^{-1}$ in the leaf chamber and a photosynthetic active radiation (PAR) of $1000 \mu \mathrm{mol} \mathrm{m}^{-2} \mathrm{~s}^{-1}$.

\section{Leaf pigment analysis}

Leaf samples $(0.1 \mathrm{~g})$ was cut into 5 -mm-long pieces and incubated in $25 \mathrm{~mL}$ of pigment extraction solution containing 1:1 $(v / v)$ acetone and anhydrous ethanol in darkness for $24 \mathrm{~h}$ at $25{ }^{\circ} \mathrm{C}$. Contents of chlorophyll a, chlorophyll b, and carotenoid in the leaves were calculated according to Arnon (1949).

\section{Total soluble sugar, free amino acid, sucrose, and soluble protein analysis}

Dry leaf sample powder $(0.1 \mathrm{~g})$ was extracted twice with $80 \%(v / v)$ ethanol at $80{ }^{\circ} \mathrm{C}$. The extraction was collected to determine the contents of total soluble sugar (TSS), sucrose, and free amino acid (FAA). The content of TSS was measured using the anthrone reagent method (Zhang et al. 2011). In general, $5 \mathrm{~mL}$ anthrone sulfuric acid solution (75 \% v:v) was added to 0.1 supernatant. The mixture was boiled in $90{ }^{\circ} \mathrm{C}$ for $15 \mathrm{~min}$, after it was refrigerated in cool water bath $\left(0{ }^{\circ} \mathrm{C}\right)$. Absorbance at $620 \mathrm{~nm}$ was read using a spectrophometer. FAA was determined with the ninhydrin reagent method (Moore and Stein 1954). One 

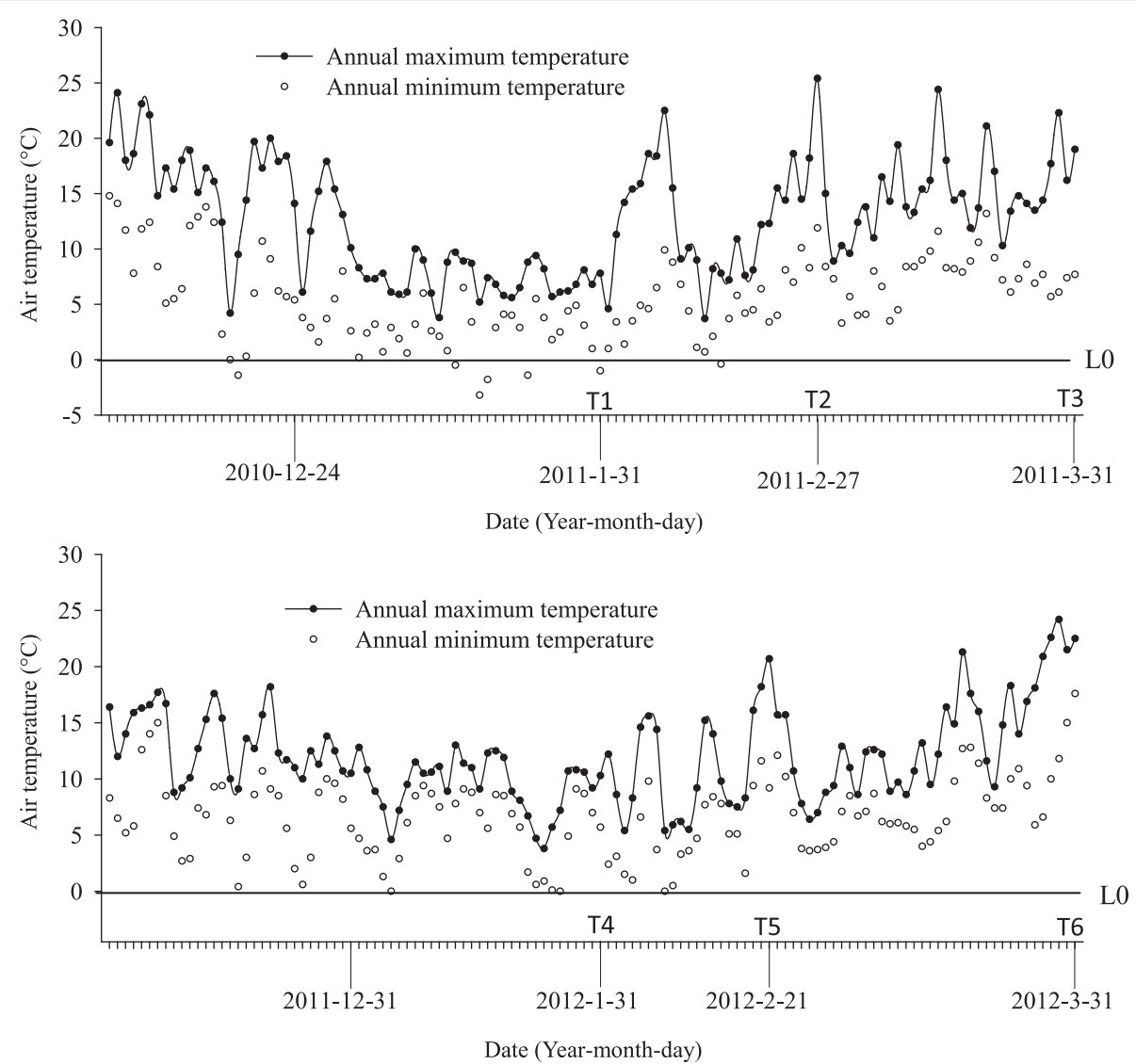

Fig. 1 Variations of the maximum mean temperature and annual minimum temperature between 2010 and 2012. L0 the line of $0^{\circ}$, T1 31 January 2011, T2 27 February 2011, T3 31 March 2011, T4 31 January 2012, T5 21 February 2012, T6 31 March 2012. The annual maximum temperature implies the daily maximum temperature, and the annual minimum temperature implies the daily minimum temperature

milliliter of acetate buffer $(\mathrm{pH}=5.4)$ and $1 \mathrm{ml}$ chromogenic agent were added to $1 \mathrm{~mL}$ FAA extraction. The mixture was heated in boiling water bath for 15 min. After being cooled in ice water, $3 \mathrm{~mL}$ ethanol $(60 \%, v / v)$ was added. The content of FAA was measured as the absorbance at $570 \mathrm{~nm}$.

Sucrose content was assayed by the method of Hendeix (1993).

Soluble protein content in leaves was determined according to Bradford (1976).

\section{Determination of activities of sucrose phosphate synthase} and sucrose synthase analysis

Sucrose phosphate synthase (SPS) activity was assayed according to Miron and Schaffer (1991), with minor modifications. The assay mixture contained $50 \mathrm{mM}$ HEPES- $\mathrm{NaOH}$ buffer (pH 7.5), $10 \mathrm{mM} \mathrm{MgCl}$, $5 \mathrm{mM}$ fructose-6-phosphate, $5 \mathrm{mM}$ glucose-6-phosphate, $5 \mathrm{mM}$ UDP-glucose, and $0.1 \mathrm{~mL}$ of enzyme extract. The mixture $(0.4 \mathrm{~mL})$ was incubated at $30{ }^{\circ} \mathrm{C}$ for $30 \mathrm{~min}$, and the reaction was terminated by the addition of $0.1 \mathrm{~mL}$ of $2 \mathrm{M} \mathrm{NaOH}$. The remaining hexose was destroyed by placing the tubes in a boiling water bath for $10 \mathrm{~min}$ and allowing them to cool. After the addition of $1 \mathrm{~mL}$ of $0.1 \%(w / v)$ resorcinol and $3.5 \mathrm{~mL}$ of $30 \%$ $(v / v) \mathrm{HCl}$, the mixture was incubated at $80{ }^{\circ} \mathrm{C}$ for $10 \mathrm{~min}$. After the tubes cooled, the absorbance of sucrose was determined at $480 \mathrm{~nm}$. The sucrose synthase (SS) assay was conducted following the same aforementioned steps, except that it contained $25 \mathrm{mM}$ fructose instead of fructose-6-phosphate and was devoid of glucose-6-phosphate.

\section{Activities of endopeptidase and carboxypeptidase analysis}

Enzymes of endopeptidase and carboxypeptidase were extracted and estimated according to the procedure of Mehta and Mattoo (1996) and Wang et al. (2003). Fresh leaves of $1 \mathrm{~g}$ were homogenized in $5 \mathrm{~mL}$ of refrigerated grinding medium containing $50 \mathrm{mM}$ Tris- $\mathrm{HCl}$ buffer, $4 \mathrm{mM}$ DTT, $1 \mathrm{mM}$ EDTA, and $1 \%$ PVP. The extraction was centrifuged at $15,000 \mathrm{rpm}$ for $30 \mathrm{~min}$, and the supernatant was collected for estimating endopeptidase and carboxypeptidase activities. 
The reaction mixture contained $0.4 \mathrm{~mL}$ of enzyme extract, 0.4 of $\mathrm{mL} 100 \mathrm{mM}$ acetate buffer $(\mathrm{pH} 4.8)$, and $0.2 \mathrm{~mL}$ of $0.05 \mathrm{M}$ bovine hemoglobin. After incubation at $38{ }^{\circ} \mathrm{C}$ for $1 \mathrm{~h}$, the reaction was terminated with the addition of $1 \mathrm{~mL}$ of $10 \%$ three chloroacetic acid, while $1 \mathrm{~mL}$ of $10 \%$ TCA was added to the control group before being heated. Then the reaction mixture was placed at $4{ }^{\circ} \mathrm{C}$ for $3 \mathrm{~min}$, and centrifuged at $4000 \times g$ for $10 \mathrm{~min}$. The final volume of the solution was used for ninhydrin reaction (Moore and Stein 1954). Endopeptidase activity was expressed as $\mu \mathrm{mol} \alpha-\mathrm{NH}_{2}$ formed $\mathrm{g}^{-1} \mathrm{FW} \mathrm{h}{ }^{-1}$. The reaction mixture for carboxypeptidase assay was similar to endopeptidase assay but it contained $0.3 \%(w / v)$ hippuryl-L-phenylalanine instead of $0.05 \mathrm{M}$ bovine hemoglobin.

\section{Data analysis}

The results were reported as mean + standard deviation (SD) of at least five replicates. One-way analysis of variance (ANOVA) using the least significant difference (LSD) test at $P<0.05$ significance level was performed to determine the effects of low temperature on leaf chilling injury and electrolyte leakage at different ages in the same year. Also, by applying multiple comparison tests for statistical analysis of all differences among means of the other parameters at the same year, which included photosynthetic parameters, proportional of photosynthetic pigment, sucrose metabolism, and protein hydrolysates. All data were conducted using the SPSS 10.0 software (Chicago, IL, USA).

\section{Results}

\section{Chilling injury}

The cold damage of $K$. obovata was expressed as the chilling injury index, and the results are shown in Fig. 2. The cold damage of $K$. obovata decreased with increasing tree ages. The most obvious symptoms of chilling damage was about $80 \%$ of leaf defoliation in the 2-yearold $K$. obovata, which resulted in a much higher cold damage index compared with that of other tree ages $(P<0.05)$. Although the cold damage index of the 5and 9-year-old $K$. obovata was significantly higher than that of the 54 -year-old $K$. obovata $(P<0.05)$, no leaves of trees at these ages were obviously withered and scorched.

Electrolyte leakage on $\mathrm{T} 1$ showed a similar pattern to the chilling injury index of $K$. obovata at different ages. Electrolyte leakage of the 2-year-old $K$. obovata was only significantly higher than that of the other ages on T4 $(P<0.05)$, whereas no statistical difference was observed between the 6-, 10-, and 55-year-old trees.

\section{Leaf gas exchange}

At the end of February (T2) and March (T3), the values of leaf $P n$ and Gs of the middle aged (5- or 9-year-old) mangroves were higher than those of the younger (2-year-old) and older (54-year-old) mangroves (Fig. 3a, b). In February, leaf $P n$ and Gs of the 2-year-old $K$. obovata were the lowest among all trees. In March 2011, 32 days after the February sample, leaf $P n$ and $G s$ of all tree ages in March significantly increased, especially for the 2- and 5-year-old trees $(P<0.05)$.

Younger trees had higher leaf $P n$ and $G s$ of $K$. obovata than older trees in February (T5) and March (T6). Leaf $P n$ and $G s$ of the 2-year-old trees were significantly higher compared with those of the 55-year-old trees at T5 and T6 $(P<0.05)$, but no significant difference was observed in the 6- and 10-year-old trees (Fig. 3b, d).

\section{Photosynthetic pigment}

At the end of February (T2), the $\mathrm{Chl} \mathrm{a/Chl} \mathrm{b}$ and chlorophyll/carotenoid (Chl/Car) ratios in leaves increased with increasing tree ages. The leaf $\mathrm{Chl} \mathrm{a} / \mathrm{Chl} \mathrm{b}$ ratios of the 5-, 9-, and 54-year-old trees were higher by 24.4,
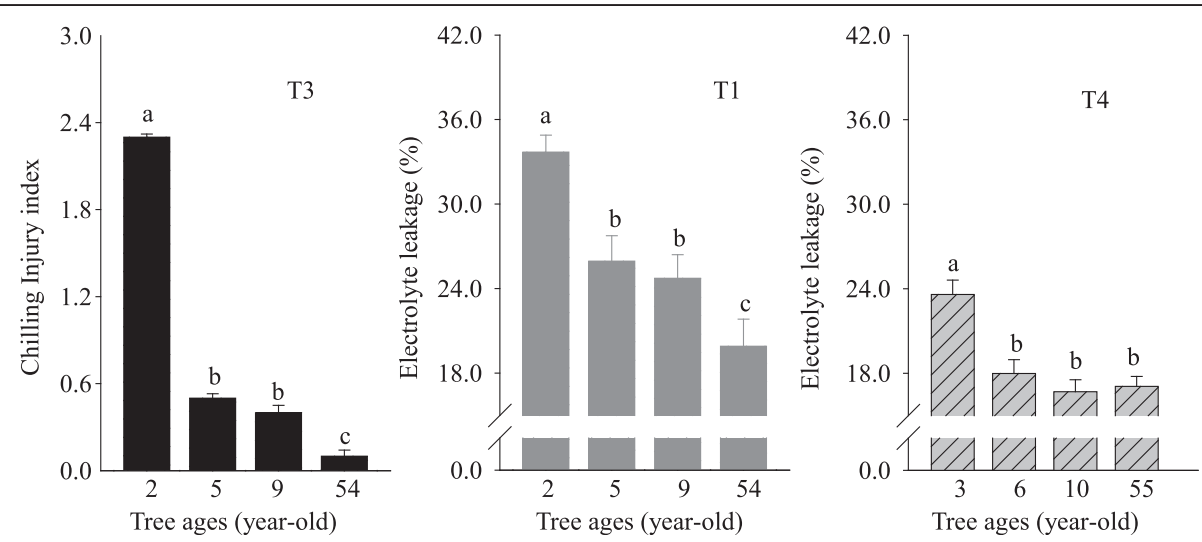

Fig. 2 Changes in chilling injury index and electrolyte leakage of $K$. obovata at different ages. Data are means + SD $(n=5)$. Different lowercase letters above the columns indicate a statistical significant difference at $P<0.05$. T1 31 January 2011, T3 31 March 2011, T4 31 January 2012 

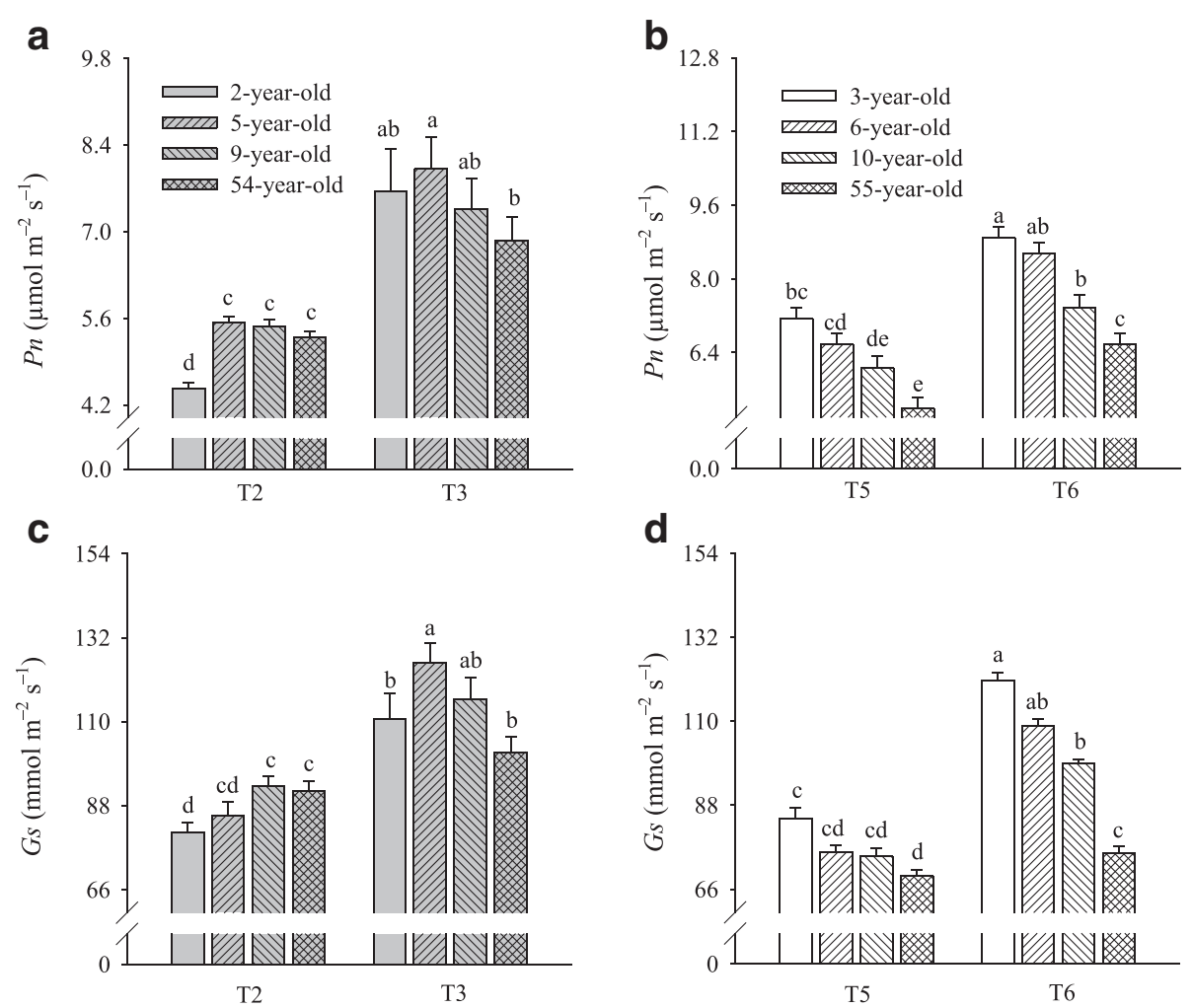

Fig. 3 Changes in leaf net photosynthetic rate $(P n)$ and stomatal conductance (Gs) of K. obovata at different ages after winter. Data are means + SD $(n=5)$. Different lowercase letters above the columns indicate a statistical significant difference at $P<0.05$. The same below. T2 27 February $2011, T 331$ March 2011, T5 21 February 2012, T6 31 March 2012. a Leaf Pn in 2011. b Leaf Pn in 2012. c Leaf Gs in 2011. d Leaf Gs in 2012

29.9 , and $34.6 \%$ than those of the 2-year-old trees, respectively, whereas the leaf $\mathrm{Chl} / \mathrm{Car}$ ratios of 5-, 9- and 54-year-old trees were higher by $11.2,10.6$, and 14.1 than those of the 2-year-old trees, respectively. However, the responses of both ratios to tree ages were opposite at the end of March (T3) (Fig. 4a, c).

Changes in the $\mathrm{Chl}$ a/Chl b ratio of $K$. obovata at different ages at T5 showed a reverse trend compared with those at T2, (Fig. 4a, b), and significant differences in the $\mathrm{Chl} \mathrm{a/Chl} \mathrm{b}$ ratio were observed among the 2-, 10-, and 55 -year-old trees. By contrast, we found no statistical difference in the Chl/Car ratio of $K$. obovata between different ages at T5. On 31 March 2012, changes in both the $\mathrm{Chl} / \mathrm{Car}$ and $\mathrm{Chl} / \mathrm{Car}$ ratios were similar to those of trees at different ages at T3 (Fig. 4d).

\section{Sucrose metabolism}

At the end of February (T2), the TSS content in the 2-year-old plant leaves was significantly lower by $22.3-34.6 \%$ than that of the other trees $(P<0.05)$, and we observed no statistical difference among the 5-, 9-, and 54-year-old trees (Fig. 5a). The leaf sucrose content increased with tree ages. Compared with the 2-year-old trees, the leaf sucrose contents of the 5-, 9-, and 54-year-old trees were higher by 8.4, 35.1 and $63.4 \%$, respectively (Fig. 5b). After 32 days, the total sugar contents of all tree leaves significantly decreased $(P<0.05)$, as well as the sucrose contents in the 9- and 54-year-old tree leaves at the end of March (T3) (Fig. 5c). At the end of March (T3), the total sugar contents increased but the sucrose contents significantly decreased with tree ages $(P<0.05)$ (Fig. 5a, c).

Compared with the 2-year-old trees, the contents of TSS and sucrose in 6-, 10-, and 55-year-old trees was significantly lower at T5 and T6 $(P<0.05)$. However, the contents of TSS and sucrose were not significantly different among the 6-, 10-, and 55-year-old trees $(P<0.05)$ (Fig. 5b, d).

At the end of February (T2), the activities of SS and SPS in leaves increased with tree ages. In detail, SS activity in the leaves of the 5-, 9- and 54-year-old trees increased by $15.1,25.4$, and $38.2 \%$, respectively, compared with those in the 2-year-old trees, whereas SPS activity increased by $8.1,61.0$, and $64.8 \%$, respectively. However, both activities were low at the end of March (T3), and the degree in the lower SS activity was more obvious than that of SPS activity (Fig. 6a, c). 

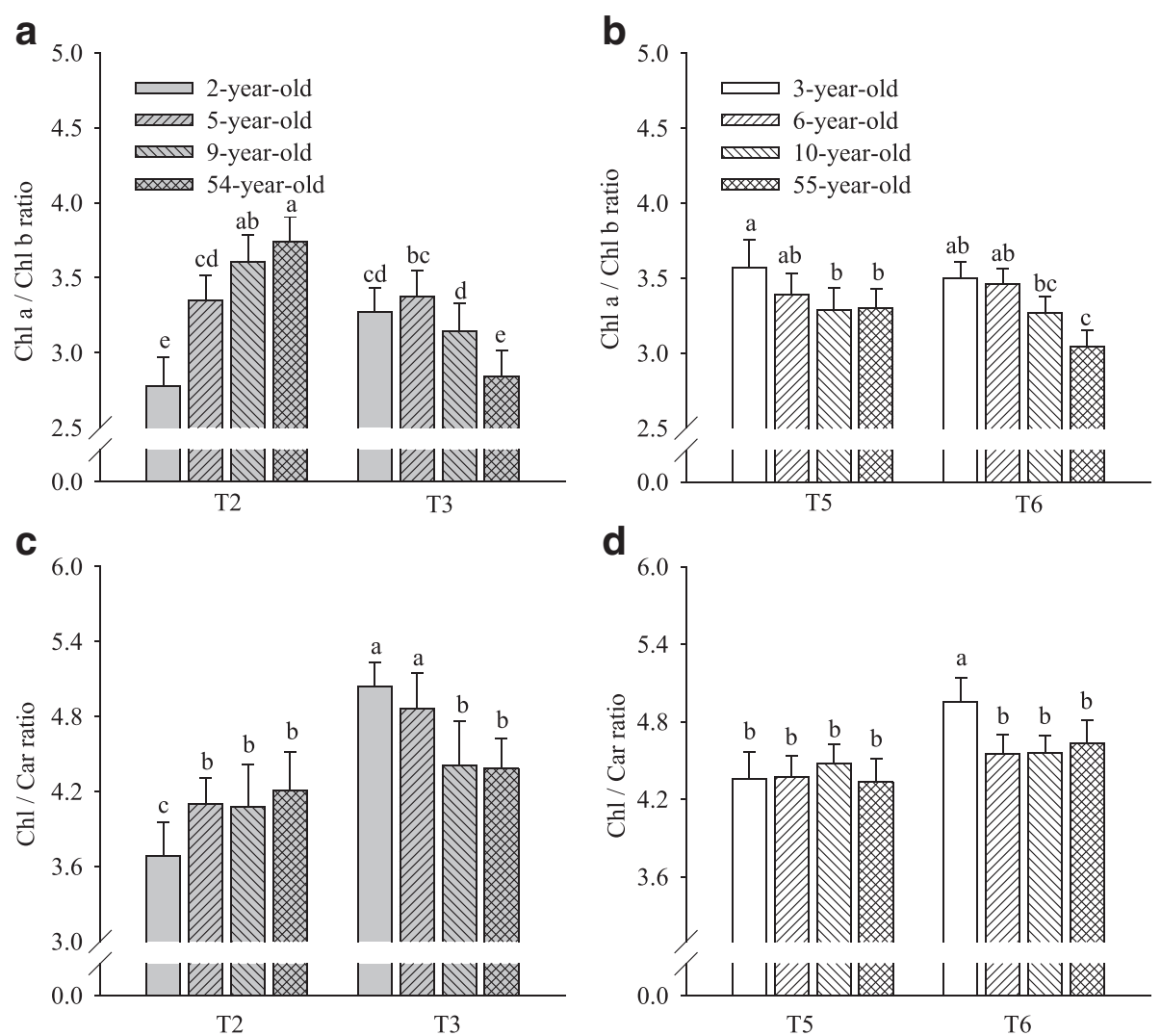

Fig. 4 Changes in the ratios of $\mathrm{Chl} \mathrm{a/Chl} \mathrm{b}$ and Chl/Car in K. obovata leaves at different ages after winter. T2 27 February 2011, T3 31 March 2011, T5 21 February 2012, T6 31 March 2012. a Leaf Chl a/Chl b ratio in 2011. b Leaf Chl a/ Chl b in 2012. c Leaf Chl/Car in 2011. d Leaf Chl/Car in 2012

SS activity in leaves also increased with tree ages at $\mathrm{T} 5$, whereas only the activity of the 2 -year-old trees was significantly higher than that of the other trees $(P<0.05)$. The significant difference in the SS activity between trees at different ages disappeared with rising temperatures (Fig. 6b, d). SPS activity in the leaves at T5 and T6 exhibited a reverse pattern to SS activity at T5, and SPS activity of 2-year-old K. obovata significantly increased compared with that of the 6-, 10-, and 55 -year-old trees at T5 and T6 $(P<0.05)($ Fig. 6b, d).

\section{Proteolytic enzymes}

In February and March, the contents of soluble protein and FAA in trees increased firstly and then decreased with tree ages. As the temperature rose, the contents of soluble protein and FAA in the 2- and 54-year-old tree leaves were unchanged, and those in the 5- and 9-yearold tree leaves showed an obvious decrease (Fig. 7a, c).

The contents of soluble protein and FAA decreased at T5 and T6 with increasing tree age (Fig. 7b, d). The contents of soluble protein and FAA in the leaves of the 2-, 6- and 10-year-old trees were significantly greater compared with those of the 55-year-old trees $(P<0.05)$, but no significant differences were observed in the contents of soluble protein and FAA among the 2-, 6-, and 10-year-old trees.

Activities of endopeptidase and carboxypeptidase in the leaves increased firstly and then decreased thereafter with tree ages in the middle of February (Fig. 8a, c). Endopeptidase activity exhibited a similar trend at the end of March, but carboxypeptidase activity showed a gradual decrease with tree ages. These findings suggested that endopeptidase activity showed no substantial difference with temperature, whereas carboxypeptidase activity showed an obvious decrease with all ages of trees.

Carboxypeptidase activity in the leaves of 2-, 6-, and 10 -year-old trees significantly increased compared with those in the leaves of the 55-year-old trees at T5 and T6 $(P<0.05)$ (Fig. 8b). However, there was only a difference between the 2-, 6-, and 10-year-old trees and 55-yearold trees in endopeptidase activity at T5 (Fig. 8d).

\section{Discussion}

Chilling injury can induce leaves to fall off and disrupt normal carbon and nitrogen metabolism of mangrove 

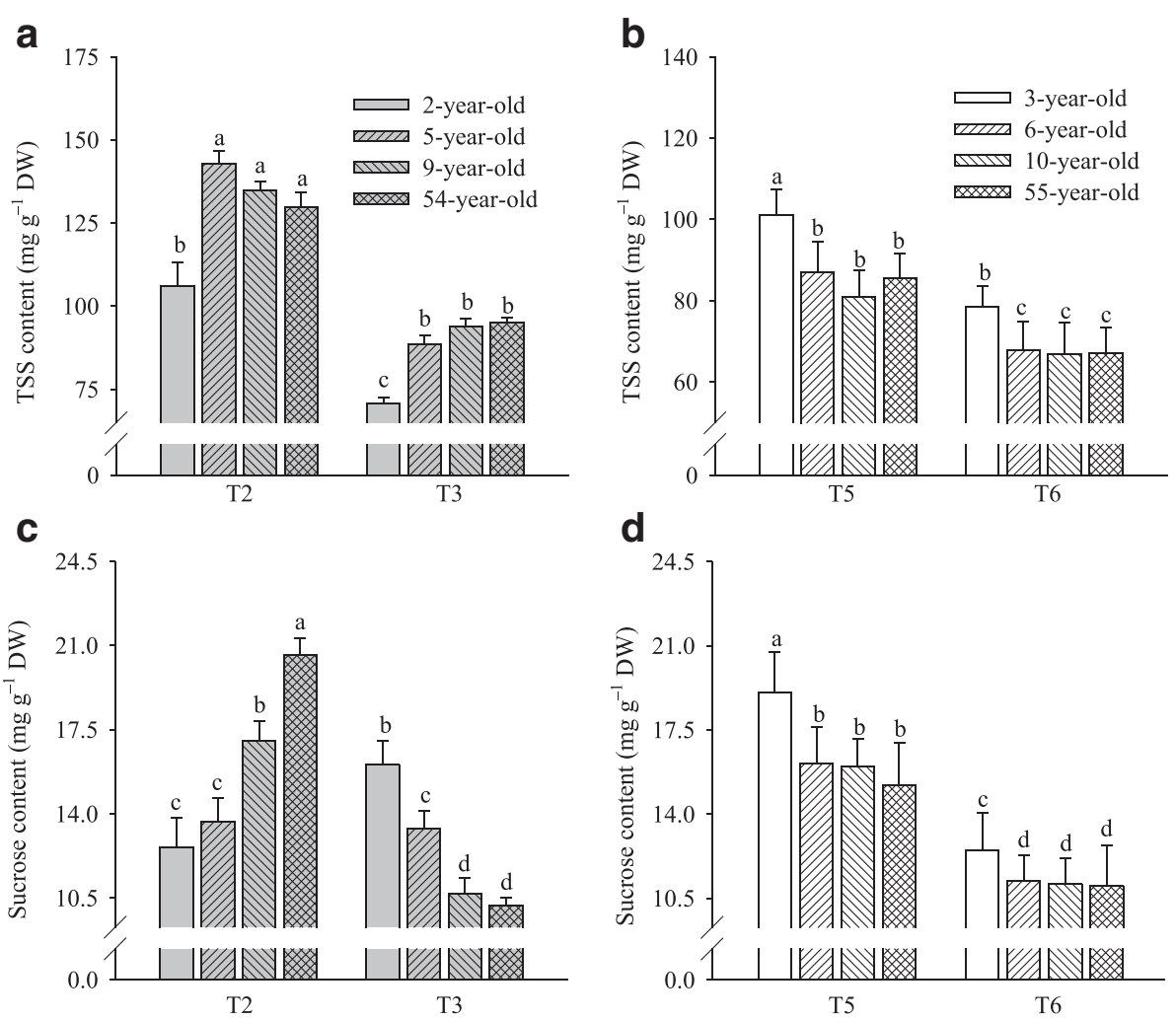

Fig. 5 Changes in contents of TSS and sucrose in K. obovata leaves at different ages after winter. T2 27 February 2011, T3 31 March 2011, T5 21 February 2012, T6 31 March 2012. a Leaf TSS content in 2011. b Leaf TSS content in 2012. c Leaf sucrose content in 2011. d Leaf sucrose content in 2012

trees, resulting in negative effects on the growth, development, and mortality of seedlings (Ellis et al. 2006; Zheng et al. 2013). Therefore, the recovery of carbon and nitrogen metabolism after winter is an important process impacting mangrove survival. Leakage of electrolytes through damaged cell membrane is well documented after exposure to freezing temperatures (Burr et al. 1990; Islam et al. 2009), and low-temperature electrolyte leakage is a good indicator of chilling tolerance during vegetative growth (Bertin et al. 1996). In the present study, the cold damage index of the 2-year-old $K$. obovata was significantly higher than that of other older (5-, 9-, and 54-year-old) trees, and electrolyte leakage in the 2-year-old trees increased by $42.8 \%$ at T1 compared with that in the same trees at T4 (Fig. 2). The most prominent symptoms of cold injury in the 2-year-old seedlings were leaf scorch and defoliation In contrast to the 2-year-old trees, the 5- and 9-year-old trees were not obviously injured and only few of them had fallen leaves. The oldest trees (54 years old) had very few yellow leaves. These results were in accordance with the changes in electrolyte leakage at T1 (Fig. 2). Thus, the resistance to leaf drop of $K$. obovata increased with tree ages. However, only leaf electrolyte leakage of the 2-year-old trees significantly increased compared with that of other trees without rare cold events in the winter of 2011 (Fig. 2).

In this study, after low temperature stress in the winters of 2010 and 2011, both $P n$ and Gs of K. obovata at different ages increased with time (Fig. 3). Similar findings have been reported in cucumber (Cucumis sativus L.) (Hu et al. 2010) and tomato (Lycopersicon esculentum Mill.) (Liu et al. 2012). In addition, we also observed that leaf $P n$ and Gs increased and then decreased with increasing tree ages in February and March of 2011, whereas leaf $P_{n}$ and Gs decreased in February and March of 2012. The two-year-old trees were found to be the most sensitive to low temperatures among the trees at different ages (Fig. 3a, c). Our results indicated that the cold rare events in the winter of 2010 changed the resilience of leaf photosynthesis by different amounts in trees of different ages.

The ratios of $\mathrm{Chl} \mathrm{a} / \mathrm{Chl} \mathrm{b}$ and $\mathrm{Chl} / \mathrm{Car}$ in plants are considered to be good indexes of photosynthetic function under chilling stress (Haldimann 1997). In the present study, we observed that the ratios of $\mathrm{Chl} \mathrm{a/Chl} \mathrm{b}$ and $\mathrm{Chl} / \mathrm{Car}$ in leaves increased with increasing tree ages on 27 February 2011. By contrast, the $\mathrm{Chl} \mathrm{a/Chl} \mathrm{b} \mathrm{ratio}$ 

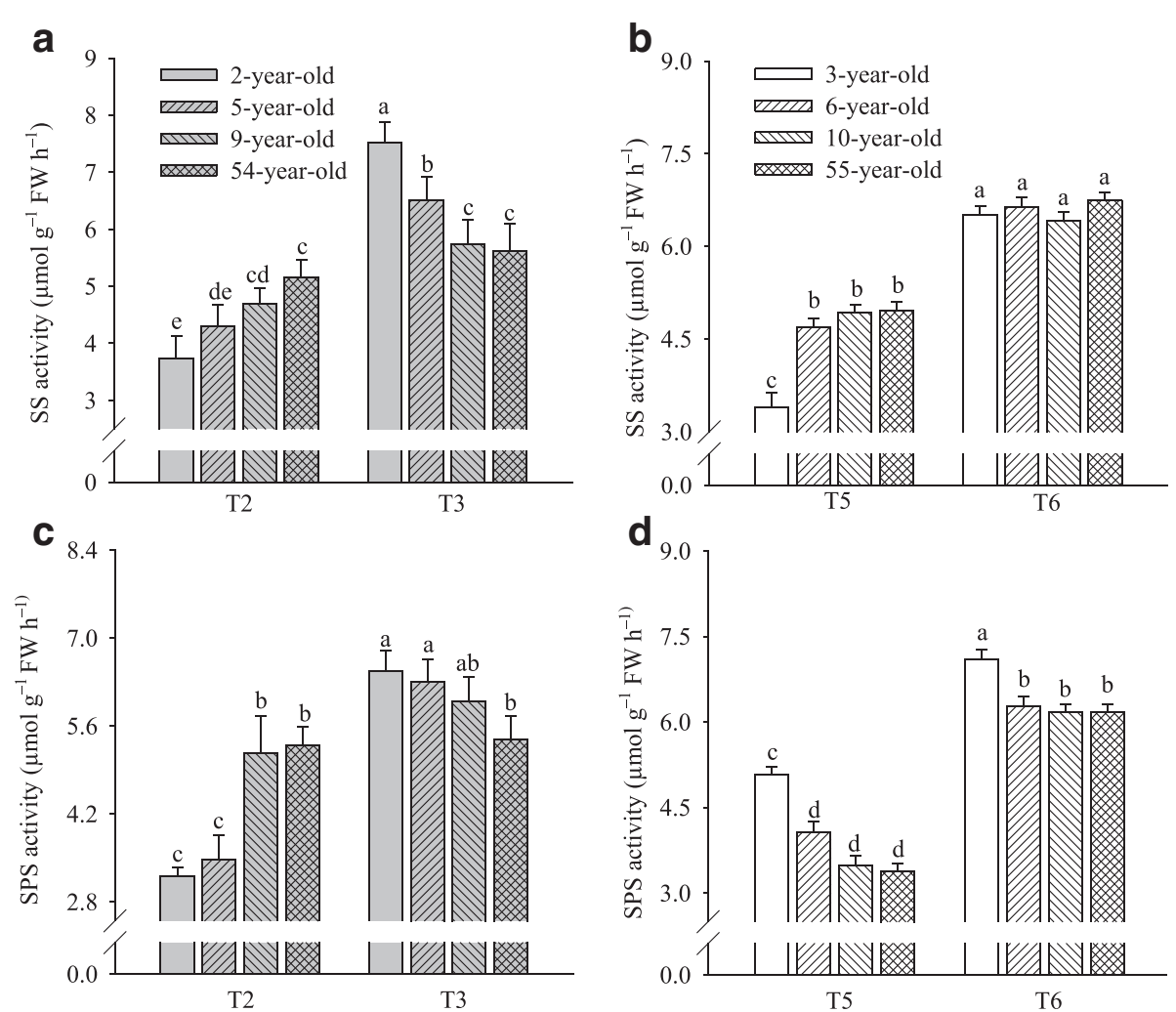

Fig. 6 Changes in activities of SS and SPS in K. obovata leaves at different ages after winter. T2 27 February 2011, T3 31 March 2011, T5 21 February 2012, T6 31 March 2012. a Leaf SS activity in 2011. b Leaf SS activity in 2012. c Leaf SPS activity in 2011. d Leaf SPS activity in 2012

showed a reverse tendency, and no significant differences in the Chl/Car ratio were observed among trees on 21 February 2012. On 31 March 2011 and 2012, the ratios of $\mathrm{Chl} \mathrm{a} / \mathrm{Chl} \mathrm{b}$ and $\mathrm{Chl} / \mathrm{Car}$ were lower for younger tree ages (Fig. 4). Our findings indicated that the biosynthesis of chlorophyll and carotenoid in seedlings from the 2-year-old trees was affected by rare cold events during the recovery period, whereas the photosynthetic parameters ( $P n$ and Gs) of the older (5-, 9- and 54-year-old) trees were not evidently changed. An appropriate ratio of $\mathrm{Chl} \mathrm{a/Chl} \mathrm{b}$ is critical in the regulation of photosynthetic antenna size (Wu et al. 2007; Oster et al. 2000). A high $\mathrm{Chl}$ a/Chl b ratio under adverse situation usually indicates a preferential decrease in lightharvesting a/b-binding proteins associated with photosystem II (PSII) and thus allowing PSII to transfer less excitation energy to the PSII core complex (Wang et al. 2011a). In the current study, the ratio of $\mathrm{Chl} \mathrm{a/Chl} \mathrm{b} \mathrm{in-}$ creased in the leaves of the 5-, 9-, and 54-year-old trees on 27 February 2011, which indicated that the total number of photosystems decreased, and light-harvesting antenna complexes in these trees might be lower than those of the 2-year-old trees. This phenomenon is also an essential protective mechanism of older (5-, 9- and 54year-old) $K$. obovata undergoing rare cold events.
However, the 2-year-old trees suffered serious injuries because of the lack of a protective mechanism under cold stress, which was proven in previous studies (Zheng et al. 2013).

As one of the main outcomes of plant photosynthesis, sucrose is influenced by activities of metabolism-related enzymes (Artuso et al. 2000; Shu et al. 2009). A previous study reported that the inhibition of SPS activity decreased the rate of sucrose synthesis in plants following exposure to chilling temperature (Van Heerden et al. 2004). In the present study, besides the sucrose content of the 2-year-old $K$. obovata leaves in 2011, the TSS and sucrose contents of leaves from trees at other ages gradually decreased with increasing temperature, which were related to increases in activities of SPS and SS in 2011 (Figs. 4 and 5). On 27 February 2011, the sucrose content increased with increasing tree ages, whereas those of trees at different ages showed a reverse pattern on 21 February 2012. In addition, we noted differences in the TSS content of trees at different ages between 2011 and 2012. A previous study demonstrated that the sucrose content in leaves is determined by the photosynthetic rate in leaves exposed to chilling temperature $(\mathrm{Du}$ and Nose 2002). According to this view, we further speculated that the rare cold events in the winter of 2010 

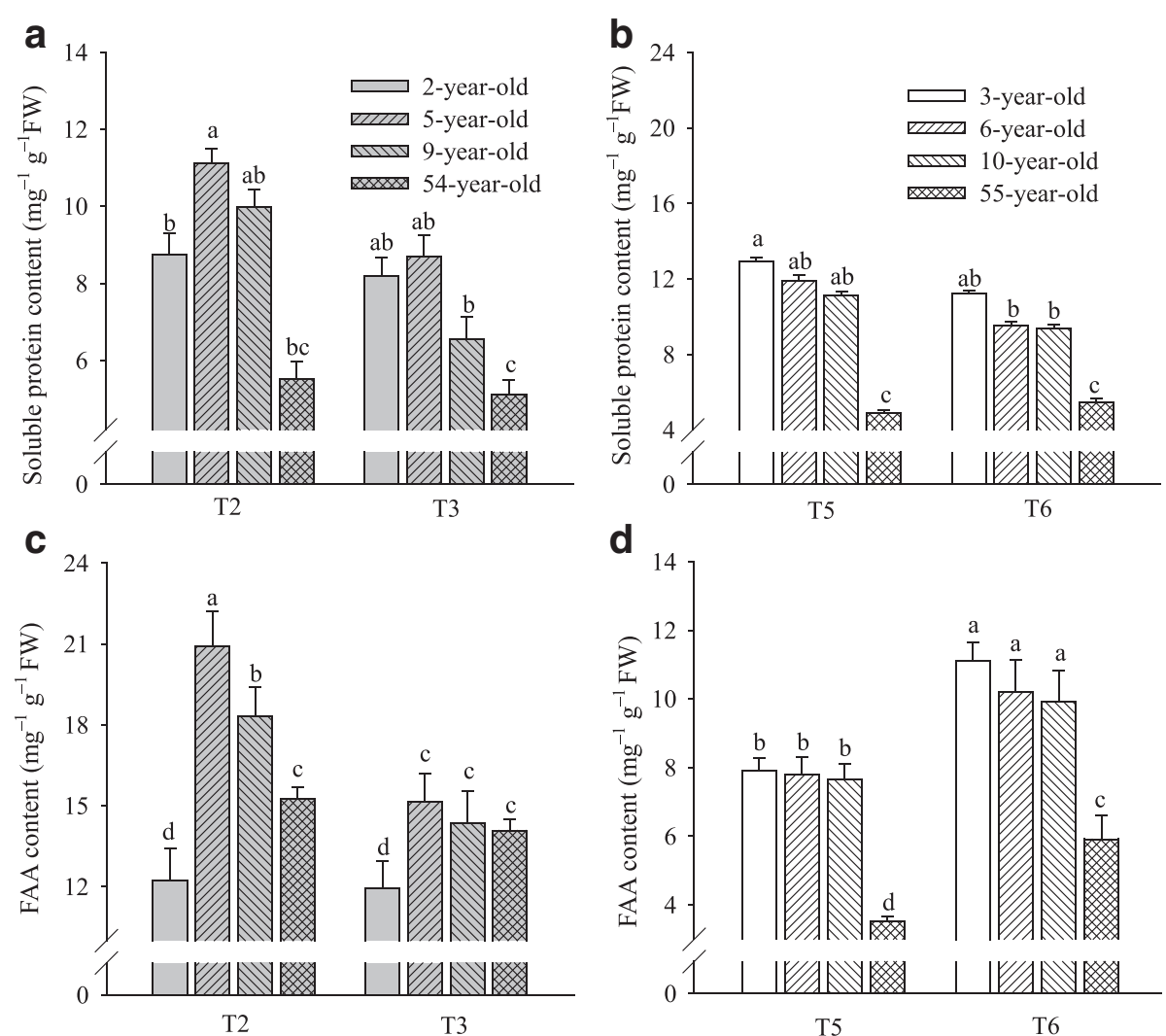

Fig. 7 Changes in contents of soluble protein and FAA in K. obovata leaves at different ages after winter. T2 27 February 2011, T3 31 March 2011, T5 21 February 2012, T6 31 March 2012. a Leaf soluble protein content in 2011. b Leaf soluble protein content in 2012. c Leaf FAA content in 2011. d Leaf FAA content in 2012

inhibited the photosynthesis of the 2-year-old $K$. obovata and affected sugar translocation. In addition, we observed that both SS and SPS activities in leaves were correlated with the synthesis of sucrose in 2011 and 2012 (Fig. 6). The activities of SS and SPS and sucrose content in leaves increased with increasing tree ages on $27 \mathrm{Feb}-$ ruary 2011, whereas SPS activity and sucrose content decreased but SS activity increased on 21 February 2012. Our findings suggested that the activities of SPS and SS were responsible for sucrose synthesis after the rare cold events in 2011, but only SPS activity was one of the main factors contributing to the metabolism of stachyose to sucrose without cold damage in 2012. In March 2011 and 2012, the activities of SS and SPS in plant leaves increased rapidly when the temperature gradually rose, and similar reductions in the activities of SPS and SS and sucrose content were observed with increasing tree ages (Fig. 6). Although the 2- and 3-year-old K. obovata trees were exposed to similar temperatures, we noted significant differences in the activities of SPS and SS and sucrose content in leaves between the 2- and 3-year-old trees. These differences were possibly due to the rare cold events in the winter of 2010. Compared with $K$. obovata on 21 February 2012, the 5-, 9-, and 54-year-old
$K$. obovata could still maintain higher photosynthetic capacity under lower temperature (in February), thereby promoting the synthesis of carbohydrates (osmotic substances) (Figs. 2, 5). The increase in osmotic substances may protect plants during rare cold events.

Lower temperatures could promote the accumulation of soluble protein and FAA in leaves of older $K$. obovata trees, which could be used to alleviate the damaging effects of cold stress (Zheng et al. 2013). In February and March of 2011 and 2012, the accumulation of soluble protein and FAA in the leaves decreased with increasing tree ages, except in the leaves from the 2-year-old $K$. obovata in February and March of 2011 (Fig. 7). These results indicated that the rare cold events could result in alterations in various important metabolic traits of the 2 -year-old seedlings, and the recovery period of the 2 -year-old trees after the rare cold events would be long. Yang and Lin (1997) speculated that the increase in proteins in cold tolerance might be associated with the degradation of high-molecular-weight proteins or generation of several novel proteins. We also observed that the leaf soluble protein content of the 2-year-old $K$. obovata was higher compared with that of the 54-year-old trees, but the FAA content in 

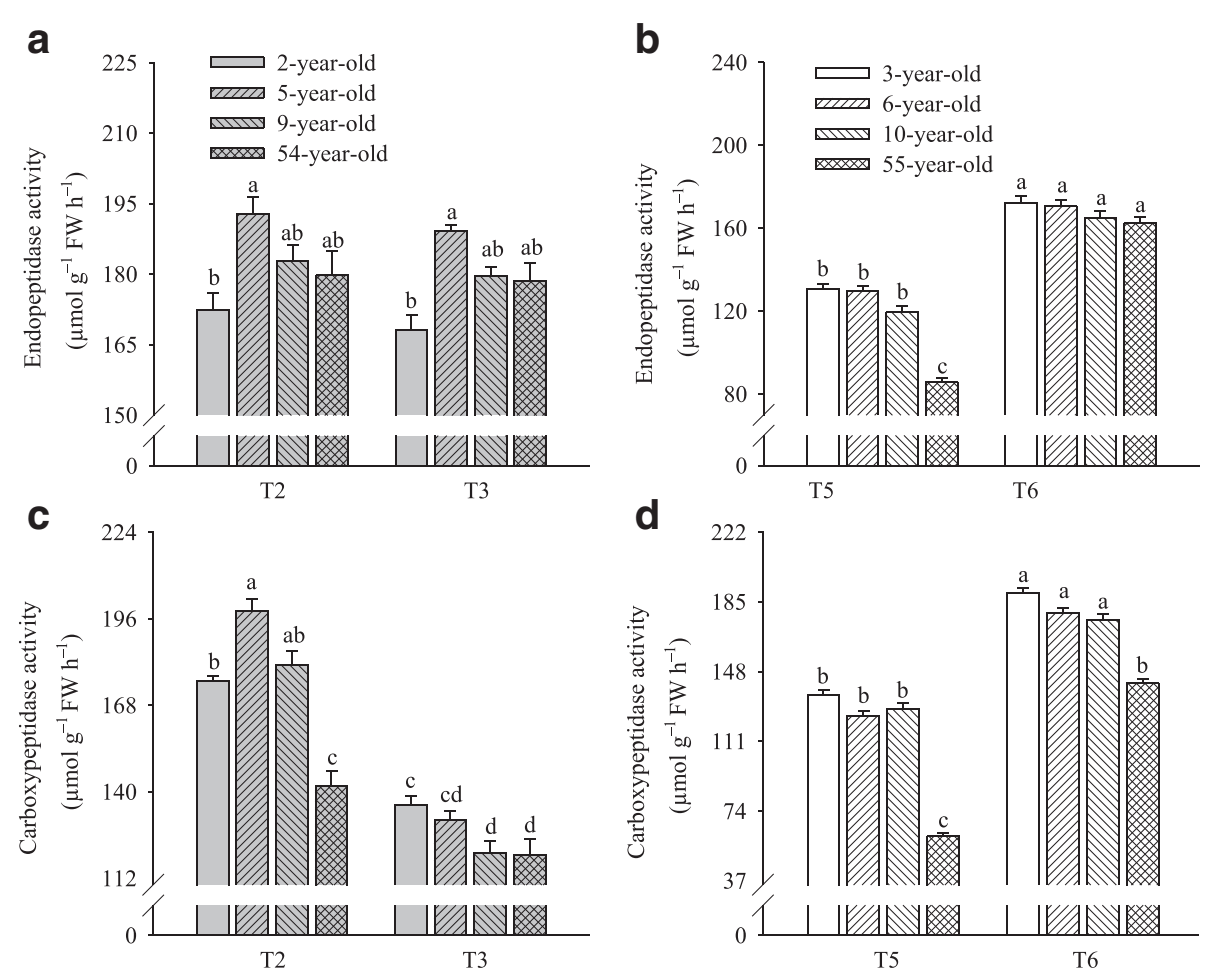

Fig. 8 Changes in activities of endopeptidase and carboxypeptidase in K. obovata leaves at different ages after winter. T2 27 February $2011, T 331$ March 2011, T5 21 February 2012, T6 31 March 2012. a Leaf endopeptidase activity in 2011. b Leaf endopeptidase activity in 2012. c Leaf carboxypeptidase activity in 2011. d Leaf carboxypeptidase activity in 2012

the leaves was lower on 27 February 2011 (Fig. 7), which was mainly caused by a reduction in endopeptidase activity. The reduction in endopeptidase activity could prevent the proteins in leaves from being broken down into small peptides. In this case, although carboxypeptidase activity was high, the synthesis of FAA was still low (Fig. 8). The contents of soluble protein and FAA in the leaves of the 54-yearold trees were in contrast to those of the 2-year-old trees (Fig. 7). This difference was largely due to the higher activities of endopeptidase and carboxypeptidase, which could complete the hydrolysis of proteins into more amino acids (Fig. 7). By analyzing the correlation with $P n$ (data not shown), we found that endopeptidase played an important role in February 2011, whereas carboxypeptidase played a more important role in March 2011. This finding suggested that the recoveries of both enzymes were closely related to temperature. However, carboxypeptidase played a more important role than endopeptidase during protein hydrolysis after winter.

\section{Conclusions}

Significant differences were observed in the recovery of carbon and nitrogen metabolism in K. obovata at different ages after winters that had cold events and that did not have extreme low temperatures. Some prominent features among them were the changes in $P n$, sucrose metabolism, and proteolysis in the leaves of the 2-year-old trees after the rare cold events in the winter of 2011. The sensitive carbon and nitrogen metabolism of the 2-yearold trees could be explained by the decreasing ratios of $\mathrm{Chl} \mathrm{a/Chl} \mathrm{b;} \mathrm{contents} \mathrm{of} \mathrm{TSS,} \mathrm{sucrose,} \mathrm{and} \mathrm{FAA;} \mathrm{and} \mathrm{activ-}$ ities of SS, SPS, endopeptidase, and carboxypeptidase.

\section{Abbreviations}

Car: carotenoid; Chl: chlorophyll; Cl: chilling injury; FAA: free amino acid; Gs: stomatal conductance; LO: the line of $0^{\circ}$; Pn: net photosynthetic rate; SPS: sucrose phosphate synthase; SS: sucrose synthase; T1: 31 January 2011; T2: 27 February 2011; T3: 31 March 2011; T4: 31 January 2012; T5: 21 February 2012; T6: 31 March 2012; TSS: total soluble sugar.

\section{Competing interests}

The authors declare that they have no competing interests.

\section{Authors' contributions}

CZ designed the study, collected and analyzed data, and drafted the manuscript. YY analyzed the experimental data, participated in the manuscript design, and helped to draft the manuscript. WL and JT participated in designing the study, analyzed the data, provided statistical assistance, and reviewed the manuscript. CZ, JQ, and JC participated in the collection of the data and analysis of the data and maintained the experimental equipment during the study. All authors have read and approved the manuscript.

\section{Acknowledgements}

This study was funded by projects of special Funding for Research of National Oceanic Public Service Industry (201505028), Zhejiang Provincial Natural Science Foundation (LQ13C030002), Science and Technology Plan 
Zhejiang Province (2012C12017-3, 2013C25096, 2014F50003), Zhejiang Province pelagic fishery (2015) "Cooperation and exchange of aquaculture technology between China and Israel based on the level of ecological system," and Wenzhou Municipal Science.

\section{Author details}

'Wenzhou Ocean Research Institute, Zhejiang Key Laboratory of Exploitation and Preservation of Coastal Bio-resource, Zhejiang Mariculture Research Institute, Wenzhou 325000, China. ${ }^{2}$ Key Laboratory of the Ministry of Education for Coastal and Wetland Ecosystem, College of the Environment and Ecology, Xiamen University, Xiamen, China. ${ }^{3}$ Nanji Islands National Marine Nature Reserve Administration, Pingyang, China. ${ }^{4}$ Wenzhou Vocational College of Science and Technology, Wenzhou, China.

\section{Received: 4 November 2015 Accepted: 24 March 2016} Published online: 03 June 2016

\section{References}

Arnon DI (1949) Copper enzymes in isolated chloroplasts. Polyphenoloxidase in Beta vulgaris. Plant Physiol 24:1-5

Artuso A, Guidi L, Soldatini GF, Pardossi A, Tognoni F (2000) The influence of chilling on photosynthesis and activities of some enzymes of sucrose metabolism in Lycopersicon esculentum Mill. Acta Physiol Plant 22:95-101.

Bradford M (1976) A rapid and sensitive method for the quantification of microgram quantities of protein utilizing the principle of protein-dye binding. Anal Biochem 72:248-254

Bertin P, Kinet JM, Bouharmont J (1996) Evaluation of chilling sensitivity in different rice varieties. Relationship between screening procedures applied during germination and vegetative growth. Euphytica 89:201-210

Burr K, Tinus RW, Wallner SJ, King RM (1990) Comparison of three cold hardiness tests for conifer seedlings. Tree Physiol 6:351-369

Chen L, Wang W, Zhang Y, Huang L, Zhao C, Yang S, Yang S, Yang Z, Chen Y, Xu H, Zhong C, Su B, Fang B, Chen N, Zeng C, Lin G (2010) Damage to mangroves from extreme cold in early 2008 in southern China. Chin J Plant Ecol 34:186-194

Chen S, Zimei L, Cui J, Ding J, Xia X, Liu D, Yu J (2011) Alleviation of chilling-induced oxidative damage by salicylic acid pretreatment and related gene expression in eggplant seedlings. Plant Growth Regul 65:101-108

Debenay JP, Marchand C, Molnar N, Aschenbroich A, Meziane T (2015) Foraminiferal assemblages as bioindicators to assess potential pollution in mangroves used as a natural biofilter for shrimp farm effluents (New Caledonia). Mar Pollut Bull 93:103-120

Du Y, Nose A (2002) Effects of chilling temperature on the activity of enzymes of sucrose synthesis and the accumulation of saccharides in leaves of three sugarcane cultivars differing in cold sensitivity. Photosynthetica 40:389-395

Ellis WL, Bowles JW, Erickson AA, Stafford N, Bell S, Thomas M (2006) Alteration of the chemical composition of mangrove (Laguncularia racemosa) leaf litter fall by freeze damage. Estuar Coast Shelf S 68:363-371

Field CD (1995) Impacts of expected climate change on mangroves. Hydrobiologia 295:75-81

Gilman EL, Ellison J, Duke NC, Field C (2008) Threats to mangroves from climate change and adaptation options: a review. Aquat Bot 89:237-250

Haldimann P (1997) Chilling-induced changes to carotenoid composition, photosynthesis and the maximum quantum yield of photosystem II photochemistry in two maize genotypes differing in tolerance to low temperature. J Plant Physiol 151:610-619

Hendeix DL (1993) Rapid extraction and analysis of nonstructural carbohydrates in plant tissues. Crop Sci 33:1306-1311

Hu W, Wu Y, Zeng J, He L, Zeng Q (2010) Chill-induced inhibition of photosynthesis was alleviated by 24-epibrassinolide pretreatment in cucumber during chilling and subsequent recovery. Photosynthetica 48:537-544

Islam MA, Apostol KG, Jacobs DF, Dumroese R (2009) Fall fertilization of Pinus resinosa seedlings: nutrient uptake, cold hardiness, and morphological development. Ann Forest Sci 66:704-704

Kao Y, Shih C, Tsai T (2004) Sensitivity to chilling temperatures and distribution differ in the mangrove species Kandelia candel and Avicennia marina. Tree Physiol 7:859-864
Levy ES, Asare NK, Yankson K, Wubah DA (2015) Effects of hydrographic conditions of ponds on juvenile fish assemblages in the Kakum mangrove system, Ghana. Region Stud Mar Sci 2:19-27

Li MS, Lee SY (1997) Mangroves of China: a brief review. Forest Ecol Manag 96:241-259

Liu K, Liu L, Liu H, Wang S (2014) Exploring the effects of biophysical parameters on the spatial pattern of rare cold damage to mangrove forests. Remote Sens Environ 150:20-33

Liu YF, Qi MF, Li TL (2012) Photosynthesis, photoinhibition, and antioxidant system in tomato leaves stressed by low night temperature and their subsequent recovery. Plant Sci 196:8-17

McMillam C (1971) Environmental factors affecting seedling establishment of the black mangrove on the central Texas coast. Ecology 52:927-930.

Mehta RA, Mattoo AK (1996) Isolation and identification of ripening-related tomato fruit carboxypeptidase. Plant Physiol 110:875-882

Miron D, Schaffer AA (1991) Sucrose phosphate synthase, sucrose synthase and invertase activities in developing fruit of Lycopersicon esculentum Mill. and the sucrose accumulating Lycopersicon hirsutum humb. and bompl. Plant Physiol 95:623-627

Moore S, Stein WH (1954) A modified ninhydrin reagent for the photometric determination of amino acids and related compounds. J Biol Chem 211:907-913

Oster U, Tanaka R, Tanaka R, Rüdiger W (2000) Cloning and functional expression of the gene encoding the key enzyme for chlorophyll b biosynthesis (CAO) from Arabidopsis thaliana. Plant J 21:305-310

Shu H, Zhou Z, Xu N, Wang Y, Zheng M (2009) Sucrose metabolism in cotton (Gossypium hirsutum L.) fibre under low temperature during fibre development. Eur J Agron 31:61-68

Thornton SR, Johnstone R (2015) Mangrove rehabilitation in high erosion areas: assessment using bioindicators. Estuar Coast Shelf S 165:176-184

Van Heerden PD, Viljoen MM, De Villiers MF, Krüger GH (2004) Limitation of photosynthetic carbon metabolism by dark chilling in temperate and tropical soybean genotypes. Plant Physiol Bioch 42:117-124

Wang X, Cai J, Jiang D, Liu F, Dai T, Cao W (2011a) Pre-anthesis high-temperature acclimation alleviates damage to the flag leaf caused by post-anthesis heat stress in wheat. J Plant Physiol 168:585-593

Wang W, You S, Wang Y, Huang L, Wang M (2011 b) Influence of frost on nutrient resorption during leaf senescence in a mangrove at its latitudinal limit of distribution. Plant Soil 342:105-115

Wang D, Yu Z, Wang X (2003) Effects of sulfur on protein accumulation in kernels of winter wheat. Acta Agron Sin 29:878-883

Wu Z, Zhang X, He B, Diao L, Sheng S, Wang J, Guo X, Su N, Wang L, Jiang L, Wang C, Zhai H, Wang J (2007) A chlorophyll-deficient rice mutant with impaired chlorophyllide esterification in chlorophyll biosynthesis. Plant Physiol 145:29-40

Yang S, Lin P (1997) Cold-resistance ability of two mangrove species Kandelia candel and Aegiceras corniculatum during their over wintering period. Chin J Appl Ecol 8:561-565

Yang S, Lin P, Nakasuga T (2001) Effect of $5^{\circ} \mathrm{C}$ night temperature on photosynthetic rate and transpiration rate of mangrove seedlings. Bull Bot Res 21:587-591

Zhang X, Jiang D, Zheng C, Dai T, Cao W (2011) Post-anthesis salt and combination of salt and waterlogging affect distributions of sugars, amino acids, $\mathrm{Na}^{+}$and $\mathrm{K}^{+}$in Wheat. J Agron Crop Sci 197:31-39

Zheng C, Liu W, Qiu J, Huang L, Huang X, Chen S (2013) Comparison of physiological characteristics of Kandelia obovata at different ages in winter in the northernmost mangrove transplanted area of China. Acta Ecol Sin 33:132-138 